\title{
Presence of $E G F R$ mutation in pathologically non-malignant specimens from computed tomography-guided lung needle biopsies
}

\author{
TSUYOSHI UENO $^{1}$, JUNICHI SOH ${ }^{1}$, TAKAO HIRAKI ${ }^{2}$, HIROAKI ASANO ${ }^{1}$, \\ KOICHI ICHIMURA ${ }^{3}$, KENTARO SHIBAMOTO ${ }^{2}$, HIDEO GOBARA ${ }^{2}$, \\ SUSUMU KANAZAWA ${ }^{2}$, SHINICHI TOYOOKA ${ }^{1}$ and SHINICHIRO MIYOSHI ${ }^{1}$ \\ Departments of ${ }^{1}$ General Thoracic Surgery, ${ }^{2}$ Radiology, and ${ }^{3}$ Pathology, Okayama University Graduate \\ School of Medicine, Dentistry and Pharmaceutical Sciences, Okayama 700-8558, Japan
}

Received August 1, 2011; Accepted October 31, 2011

DOI: $10.3892 / 01.2011 .471$

\begin{abstract}
Activating mutations of the epidermal growth factor receptor $(E G F R)$ gene are characteristic of non-small cell lung cancer (NSCLC). EGFR mutations were previously detected in histologically normal lung tissue around NSCLC tumors. Computed tomography-guided lung needle biopsy (CTNB) is an accurate and useful technique for the diagnosis of lung tumors. However, pathologically non-malignant cases occasionally become apparent following lung tumor resection. In this study, we determined the EGFR mutational status of lung tumors diagnosed as non-malignant in CTNB specimens, but diagnosed as NSCLC following surgical resection. Between 2000 and 2008, 1,109 CTNBs were performed at Okayama University Hospital. Among them, 15 cases were initially diagnosed as non-malignant by CTNB, but diagnosed as NSCLC following surgical resection as a result of a high likelihood of malignancy by clinical findings. Twelve paired DNAs of CTNB and corresponding resected specimens were available to examine the EGFR mutational status using a mutant-enriched PCR assay. EGFR mutations were detected in one out of $12 \mathrm{CTNB}$ specimens and three of the corresponding resected tumors. This case harbored the same EGFR mutation in the CTNB specimen and resected tumor, but not in the distant corresponding nonmalignant lung tissue. Our results indicated that the detection of EGFR mutations may therefore aid the diagnosis of NSCLC in pathologically non-malignant CTNB specimens.
\end{abstract}

Correspondence to: Dr Shinichi Toyooka, Department of General Thoracic Surgery, Okayama University Graduate School of Medicine, Dentistry and Pharmaceutical Sciences, 2-5-1 Shikata-cho, Kita-ku, Okayama 700-8558, Japan

E-mail: toyooka@md.okayama-u.ac.jp

Key words: non-small cell lung cancer, epidermal growth factor receptor, computed tomography-guided lung needle biopsy

\section{Introduction}

Activating mutations of the epidermal growth factor receptor $(E G F R)$ gene are specific to non-small cell lung cancer (NSCLC), particularly adenocarcinoma (1), indicating its diagnostic value for lung tumor. The status of $E G F R$ mutation is also therapeutically significant for the selection of patients for treatment with EGFR tyrosine kinase inhibitors (EGFR-TKIs) (2). Approximately $90 \%$ of $E G F R$ mutations are composed of either in-frame deletions in exon 19 or a specific missense mutation in exon 21 (L858R) (1-3). Direct DNA sequencing is the most accurate detection assay for EGFR mutations, although we and others have developed a number of highly sensitive assays capable of detecting extremely low numbers of EGFR mutant alleles among numerous wild-type alleles (4-7). Of note, EGFR mutations were previously detected in histologically normal respiratory epithelium surrounding histologically malignant regions (8).

Computed tomography (CT) imaging enables small lung tumors to be identified (9). CT-guided lung needle biopsy (CTNB) is useful for the pathological diagnosis of such tumors $(10,11)$. However, correct diagnosis of tumors is occassionally impossible since there are no malignant cells in the CTNB specimens, particularly when materials are insufficient. CTNB specimens may also be used for molecular analysis, including those for genetic mutations $(4,5)$. We previously demonstrated that $E G F R$ mutations are capable of being detected in CTNB specimens even when the proportion of cancer cells is low, suggesting that the detection of EGFR mutations in the cells aids the diagnosis of NSCLC $(4,7)$.

In this study, the EGFR mutational status of pathologically non-malignant CTNB specimens were examined using a modified mutant-enriched polymerase-chain reaction(PCR) assay and compared with the EGFR mutational status of surgically resected tumors that had a pathological diagnosis of NSCLC.

\section{Materials and methods}

Materials. Between April 2000 and August 2008, CTNB for lung tumors was performed in 1,109 patients at Okayama 
Table I. Clinical characteristics of 12 computed tomography-guided lung needle biopsy specimens diagnosed as non-malignant.

\begin{tabular}{|c|c|c|c|c|c|c|c|c|}
\hline \multirow[t]{2}{*}{ Case } & \multirow[t]{2}{*}{ Age } & \multirow[t]{2}{*}{ Gender } & \multirow[t]{2}{*}{ Smoking status } & \multirow[t]{2}{*}{${ }^{\mathrm{a}} \mathrm{p}$-Stage } & \multirow[t]{2}{*}{ Histology of resected specimens } & \multirow[t]{2}{*}{ Size $(\mathrm{mm})$} & \multicolumn{2}{|c|}{ EGFR mutation } \\
\hline & & & & & & & $\overline{\text { Tumor }}$ & $\overline{\mathrm{CTNB}}$ \\
\hline 1 & 61 & $\mathrm{~F}$ & Never & IA & $\mathrm{AD}$ & 11 & ex19 del. & ex19 del \\
\hline 2 & 77 & M & Ever & IA & $\mathrm{AD}$ & 13 & ex19 del. & WT \\
\hline 3 & 75 & M & Ever & IA & $\mathrm{AD}$ & 22 & ex19 del. & WT \\
\hline 4 & 76 & $\mathrm{~F}$ & Never & IA & $\mathrm{AD}$ & 12 & WT & WT \\
\hline 5 & 70 & M & Ever & IA & $\mathrm{AD}$ & 14 & WT & WT \\
\hline 6 & 76 & M & Ever & IA & SQ & 15 & WT & WT \\
\hline 7 & 57 & M & Ever & IB & $\mathrm{AD}$ & 40 & WT & WT \\
\hline 8 & 75 & M & Ever & IA & $\mathrm{AD}$ & 30 & WT & WT \\
\hline 9 & 72 & $\mathrm{~F}$ & Never & IA & $\mathrm{AD}$ & 12 & WT & WT \\
\hline 10 & 77 & M & Ever & IA & $\mathrm{AD}$ & 22 & WT & WT \\
\hline 11 & 58 & M & Ever & IA & $\mathrm{AD}$ & 13 & WT & WT \\
\hline 12 & 73 & M & Ever & IA & $\mathrm{AD}$ & 10 & WT & WT \\
\hline
\end{tabular}

F, female; M, male; Never, never-smoker; Ever, ever-smoker; AD, adenocarcinoma; SQ, squamous cell carcinoma; Size, tumor diameter in surgically resected specimens; Tumor, specimen of surgically resected tumor; CTNB, computed tomography-guided lung needle biopsy; ex19 del., exon 19 deletion; WT, wild-type. ${ }^{\mathrm{a} p}$-Stage, pathological stage was determined according to International Union Against Cancer TNM classification of malignant tumors (6th edition).

University Hospital (Japan). Histological diagnosis was determined using hematoxylin and eosin (H\&E)-stained sections of CTNB specimens and surgically resected tumors. Of these tumors, 24 tumors were diagnosed as non-malignant, but the clinical findings suggested a high likelihood of malignancy. Finally, 15 of the 24 tumors were diagnosed as primary lung cancer. Twelve of the tumors were available for further study. The clinical data of these 12 cases are shown in Table I. DNA was extracted from the paraffin-embedded specimens of the CTNB and the surgically resected tumors without microdissection using the QIAamp ${ }^{\circledR}$ DNA FFPE tissue kit (Qiagen Inc., Valencia, CA, USA) according to the manufacturer's instructions.

Methods. EGFR gene mutations in exons 19 and 21 were determined using mutant-enriched PCR, a two-step PCR with intermittent restriction digestion to selectively eliminate wildtype alleles and to enrich mutated alleles $(4,7)$. Our previously developed mutant-enriched PCR assay was initially used on all 12 CTNB samples. However, amplification was not achieved in some CTNB samples, particularly when they were small specimens. Therefore, we developed a modified mutant-enriched PCR to detect exon 19 deletions in which the amplicon was shorter than that of the previous version (79 bp versus $138 \mathrm{bp}$ ). Primer sequences were as follows: 5'-AAGATAAAATTCCCGTCGCT-3' (forward primer) and 5'-CTCACATCGAGGATTTCCTTG-3' (reverse primer), and PCR conditions were the same as those of our previous study. The first round of amplification used 5-100 ng sample DNA, $150 \mu \mathrm{mol} / 1$ deoxynucleotide triphosphate, 2 pmol of each primer and 0.25 units HotStarTaq DNA polymerase (Qiagen, Inc.). Intermittent restriction digestion of $2 \mu \mathrm{l}$ first-round PCR products was carried out with $10 \mathrm{IU} \mathrm{MseI}$ at $37^{\circ} \mathrm{C}$ for $6 \mathrm{~h}$. An aliquot of first-round PCR product was used as a template for second-round amplification under the same conditions as the first-round PCR. The product of the second amplification was analyzed by ethidium bromide staining of $12 \%$ polyacrylamide gel electrophoresis and reproducibility was confirmed in two independent experiments.

\section{Results}

Clinical characteristics. The histological diagnoses of CTNB specimens and surgically resected specimens were re-evaluated to confirm that the CTNB samples of all 12 cases showed no malignancy, whereas all of the pathological diagnoses of corresponding resected specimens were NSCLCs. The characteristics of the cases are shown in Table I.

Mutations. We determined the EGFR mutational status of 12 surgically resected specimens, and identified three deletions in exon 19 (25\%), but no EGFR exon 21 L858R mutations. The mutational status of CTNB samples was blindly evaluated using the modified mutant-enriched PCR assay, with the finding that one sample harbored an EGFR exon 19 deletion (8.3\%). This result was confirmed in two independent experiments. The histological images of CTNB and the resected tumor of Case 1 are shown in Fig. 1. The pathological findings of the Case 1 tumor revealed a clear separation of malignant and non-malignant cell areas (Fig. 1A). Of note, the same type of EGFR exon 19 deletion (E746 to A750) was present in the CTNB specimen and the resected tumor of Case 1 (Fig. 2, sequencing data is not shown). In addition, the EGFR mutation was not present in the distant peripheral normal lung 


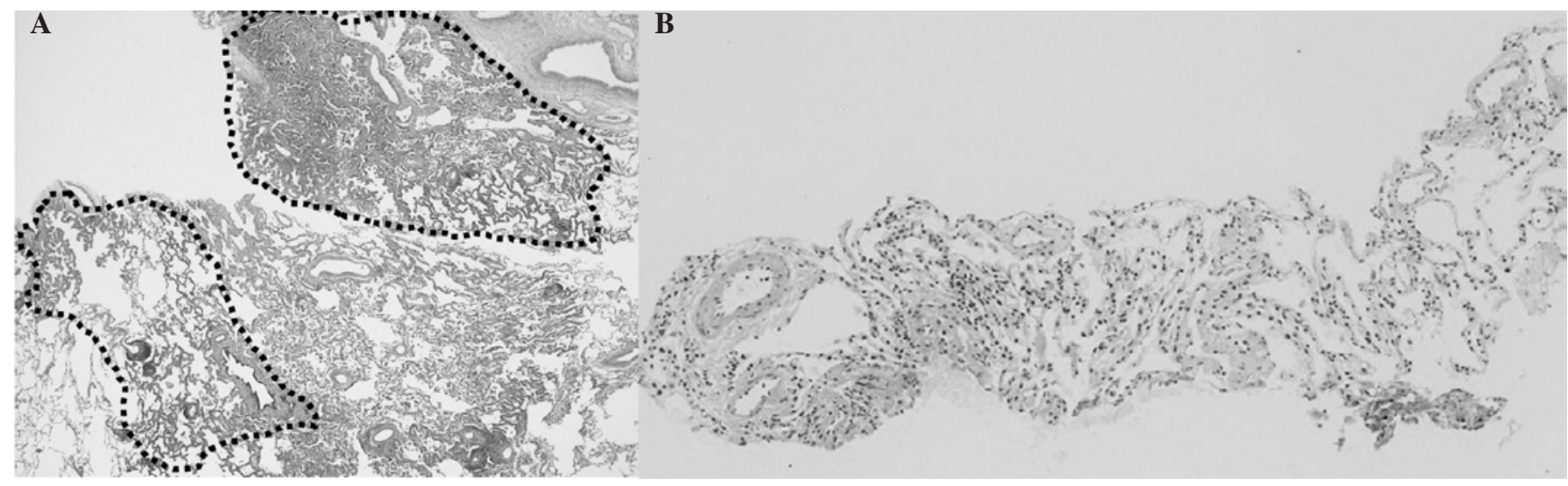

Figure 1. Microscopic findings of (A) the surgically resected and (B) computed tomography-guided lung needle biopsy (CTNB) specimens in Case 1. The portion circled by the black dotted line revealed malignant tumor cells in the surgically resected specimen. Malignant cells were not detected in the CTNB specimen. Magnification, $\mathrm{x} 2$ and $\mathrm{x} 4$, respectively.

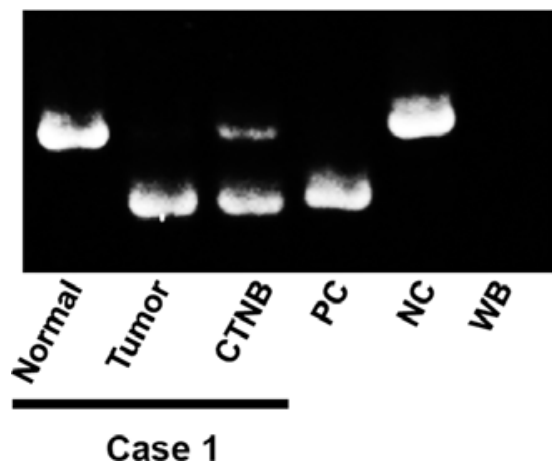

79 bp (wild-type) 64 bp (mutant)

Figure 2. Results of the mutant-enriched assay in the surgical and computed tomography-guided lung needle biopsy (CTNB) specimens in Case 1. Normal, normal section of surgically resected lung tissue distant from tumor; Tumor, specimen of surgically resected tumor; CTNB, CTNB specimen PC, positve control; NC, negative control; WB, water blank. EGFR exon 19 deletions were present in both the CTNB specimen and surgically resected tumor in the same case using a modified mutant-enriched PCR assay. PCR, polymerase-chain reaction.

tissue of Case 1. No EGFR mutation was found in the CTNB samples of Cases 2 and 3.

\section{Discussion}

The detection of $E G F R$ mutations is crucial for the diagnosis of NSCLC as well as for selecting patients for EGFR-TKI treatment $(2,12,13)$. Sensitive assays have been developed to detect $E G F R$ mutations in small clinical samples that are assumed to contain numerous non-malignant cells, including CTNB specimens, pleural effusion and circulating tumor cells $(4-7,14)$. In the present study, EGFR mutations were detected in pathologically non-malignant CTNB specimens using our modified mutant-enriched PCR assay. This finding may be explained in two ways: i) the presence of a small portion of malignant cells only in DNA-extracted sections and not in the H\&E-stained section, ii) the presence of EGFR mutations in the lung tissue of normal-appearing surrounding tumor tissue harboring EGFR mutations. The latter is supported by a previous study by Tang et al (8).
These authors determined EGFR mutational status in 21 lung adenocarcinoma cases and their adjacent and distant normal lung tissues to find that EGFR mutations were present in $43 \%$ of adenocarcinomas, $24 \%$ of adjacent normal tissues and none of the distant tissues (8). These authors also reported that the mutational patterns in the tumors and corresponding adjacent, non-malignant specimens were identical. Of note, more frequent mutations affecting normal epithelium were found in exon 19 (54\%) compared with exon 21 (7\%). The mutational type of the mutant case in this study in a nonmalignant CTNB specimen was also an exon 19 deletion. Our results support the hypothesis that a localized type of field effect phenomenon may exist for EGFR mutations in the lung respiratory epithelium surrounding lung adenocarcinomas (8).

Our results also have clinical implications. The administration of EGFR-TKIs is recommended for patients with EGFR mutation and is exclusively found in NSCLC (15). Thus, detection of an $E G F R$ mutation from lung tumors may be considered to be NSCLC. As shown, sensitive assays may be capable of detecting EGFR mutations from pathologically non-malignant CTNB specimens, resulting in avoidance of additional invasive procedures for patients. Our study suggests that the EGFR mutation should be analyzed even in biopsied specimens with non-malignant diagnosis to determine whether patients should be treated with EGFR-TKI when they are clinically suspected as having NSCLC.

\section{Acknowledgements}

We would like to thank Ms. Fumiko Isobe, General Thoracic surgery and Mr. Tetsushi Iwasa, Central Research Laboratory, Okayama University Graduate School of Medicine, Dentistry and Pharmaceutical Sciences for their excellent technical support.

\section{References}

1. Kosaka T, Yatabe Y, Endoh H, Kuwano H, Takahashi T and Mitsudomi T: Mutations of the epidermal growth factor receptor gene in lung cancer: biological and clinical implications. Cancer Res 64: 8919-8923, 2004. 
2. Paez JG, Janne PA, Lee JC, Tracy S, Greulich H, Gabriel S, Herman P, Kaye FJ, Lindeman N, Boggon TJ, et al: EGFR mutations in lung cancer: correlation with clinical response to gefitinib therapy. Science 304: 1497-1500, 2004

3. Tokumo M, Toyooka S, Kiura K, Shigematsu H, Tomii K, Aoe M, Ichimura K, Tsuda T, Yano M, Tsukuda K, et al: The relationship between epidermal growth factor receptor mutations and clinicopathologic features in non-small cell lung cancers. Clin Cancer Res 11: 1167-1173, 2005.

4. Asano H, Toyooka S, Tokumo M, Ichimura K, Aoe K, Ito S, Tsukuda K, Ouchida M, Aoe M, Katayama H, et al: Detection of EGFR gene mutation in lung cancer by mutant-enriched polymerase chain reaction assay. Clin Cancer Res 12: 43-48, 2006.

5. Shih JY, Gow CH, Yu CJ, Yang CH, Chang YL, Tsai MF, Hsu YC, Chen KY, Su WP and Yang PC: Epidermal growth factor receptor mutations in needle biopsy/aspiration samples predict response to gefitinib therapy and survival of patients with advanced nonsmall cell lung cancer. Int J Cancer 118: 963-969, 2006.

6. Soh J, Toyooka S, Aoe K, Asano H, Ichihara S, Katayama H, Hiraki A, Kiura K, Aoe M, Sano Y, et al: Usefulness of EGFR mutation screening in pleural fluid to predict the clinical outcome of gefitinib treated patients with lung cancer. Int J Cancer 119: 2353-2358, 2006.

7. Otani H, Toyooka S, Soh J, Yamamoto H, Suehisa H, Kobayashi N, Gobara H, Mimura H, Kiura K, Sano Y, et al: Detection of EGFR gene mutations using the wash fluid of CT-guided biopsy needle in NSCLC patients. J Thorac Oncol 3: 472-476, 2008.

8. Tang X, Shigematsu H, Bekele BN, Roth JA, Minna JD, Hong WK, Gazdar AF and Wistuba II: EGFR tyrosine kinase domain mutations are detected in histologically normal respiratory epithelium in lung cancer patients. Cancer Res 65 7568-7572, 2005.
9. Edey AJ and Hansell DM: Incidentally detected small pulmonary nodules on CT. Clin Radiol 64: 872-884, 2009.

10. Uskul BT, Turker H, Gokce M, Kant A, Arslan S and Turan FE: CT-guided transthoracic fine needle aspiration of pulmonary lesions: accuracy and complications in 134 cases. Tuberk Toraks 57: 177-185, 2009.

11. Hiraki T, Mimura H, Gobara H, Iguchi T, Fujiwara H, Sakurai J, Matsui Y, Inoue D, Toyooka S, Sano Y, et al: CT fluoroscopyguided biopsy of 1,000 pulmonary lesions performed with 20-gauge coaxial cutting needles: diagnostic yield and risk factors for diagnostic failure. Chest 136: 1612-1617, 2009.

12. Lynch TJ, Bell DW, Sordella R, Gurubhagavatula S, Okimoto RA, Brannigan BW, Harris PL, Haserlat SM, Supko JG, Haluska FG, et al: Activating mutations in the epidermal growth factor receptor underlying responsiveness of non-small-cell lung cancer to gefitinib. N Engl J Med 350: 2129-2139, 2004.

13. Maemondo M, Inoue A, Kobayashi K, Sugawara S, Oizumi S, Isobe $\mathrm{H}$, Gemma A, Harada M, Yoshizawa H, Kinoshita I, et al: Gefitinib or chemotherapy for non-small-cell lung cancer with mutated EGFR. N Engl J Med 362: 2380-2388, 2010.

14. He C, Liu M, Zhou C, Zhang J, Ouyang M, Zhong N and Xu J: Detection of epidermal growth factor receptor mutations in plasma by mutant-enriched PCR assay for prediction of the response to gefitinib in patients with non-small-cell lung cancer. Int J Cancer 125: 2393-2399, 2009.

15. Lee JW, Soung YH, Kim SY, Park WS, Nam SW, Lee JY, Yoo NJ and Lee SH: Absence of EGFR mutation in the kinase domain in common human cancers besides non-small cell lung cancer. Int J Cancer 113: 510-511, 2005. 